\title{
Direct Torque Control for Induction Motor Drive with Reduced Torque and Flux Ripples
}

\author{
Chinmaya Kulkarni, Gurubasu Hombal, Sachin Angadi, A. B. Raju
}

\begin{abstract}
The most universally used electric motor is an induction motor fed with three phase supply and eighty percent of mechanical power utilized by industries is given by three phase asynchronous ac motor. Direct torque control method is one such technique for controlling flux and torque of an asynchronous motor fed with PWM VSI. Without any complex control algorithms, it provides easy commands for the control of induction motor flux as well as torque. We are demonstrating the principle of DTC of an asynchromous motor using three level hysteresis controller in this paper. Philosophy of DTC with aforementioned control method has been simulated using MATLAB/Simulink.
\end{abstract}

Key-words: Direct Torque Control, Inverter, and Hysteresis Controller, rotating magnetic field.

\section{INTRODUCTION}

Induction motors are economical, rugged in construction, and reliable. Actually, towards the fact that separate control of torque as well as flux in the separately excited dc drives turns to be easier to control. Due to high efficiency and simplicity, the induction motors are utilized in various applications. The dynamic performance of an asynchronous motor is non-linear due to the interdependency of electrical as well as mechanical variables. All the above-mentioned factors make robust the control design of an induction motor when high speed and high precision are expected.

The Induction motor has two control strategies, first is scalar control as well as second is vector control. Scalar control is simple to execute and provides a sluggish response because the inherent coupling effect and the system are easily inclined to instability. The previously stated problems can be eliminated by using vector control. In this technique an induction motor can be handled similarly that of a separately excited dc motor, taken recovery within the large capability of ac drives. In vector control there are two types, one is field-oriented control and other is the direct torque control. This paper completely explains the direct torque control for asynchronous motor. As title signifies, it directly controls the torque and stator flux of an asynchronous motor drive fed through inverter.

The fundamental concept of direct torque control is towards direct selection of stator voltage vectorsaccording to the difference within torque and stator flux linkages. Within

Revised Manuscript Received on March 5, 2020.

* Correspondence Author

ChinmayaKulkarni,ElectricalandElectronicsEngg,KLE Technological University, Hubli, India. Email: chinmayakulkarni8@gmail.com

GurubasuHombal,Electrical and Electronics Engg, KLE Technological University, Hubli, India. Email: gurubasu.hombal@.kletech.ac.in

Sachin Angadi, Electrical and Electronics Engg, K L E Technological University, Hubli, India. Email: Sachin@kletech.ac.in

A. B. Raju, Electrical and Electronics Engg, K L E Technological University, Hubli, India. Email: abraju @kletech.ac.in
DTC, stator flux and torque are calculated. The miscalculations of torque and flux are limited within the hysteresis band. Direct torque control has advantages such as lower parameter dependence, steady-state efficiency, quick torque response and simpler in the configuration.

The present article is structured as follows:In section IIDesign and Implementation of Induction Motor, section III Induction Motor model, Section IV Block Diagram of DTC (Direct Torque Control), section V Design of feedback system, section VI Modeling of inverter, section VII case study, section VIII Simulation results and in section IX Conclusion.

\section{DESIGN AND IMPLEMENTATION OF INDUCTION MOTOR}

When the stator terminals of the induction motor are linked to three phase supply, the balanced three phase currents starts to flow in the armature winding and hence a rmf is developed. The rotating magnetic field revolves at synchronous speed $\left(\mathrm{N}_{\mathrm{s}}\right)$ in $\mathrm{rpm}$.

$N_{s}=\frac{120 f}{P}$

F: Supply frequency

P: Number of Poles in induction motor

The imbalance within the rotor speed and the stator speed describes slip (s) in per unit wherein

$s=\frac{\omega_{s}-\omega}{\omega_{s}}$

$\omega_{\mathrm{s}}$ : synchronous speed in rps,

$\omega_{\mathrm{r}}$ : rotor speed in rps.

At rotor speed is zero, unity slip is obtained. At rotor running at speed approximately near to the synchronous speed then the slip is approximately zero. Therefore the slip lies between 0 and 1 (i.e., $0<\mathrm{s}<1$ ). 


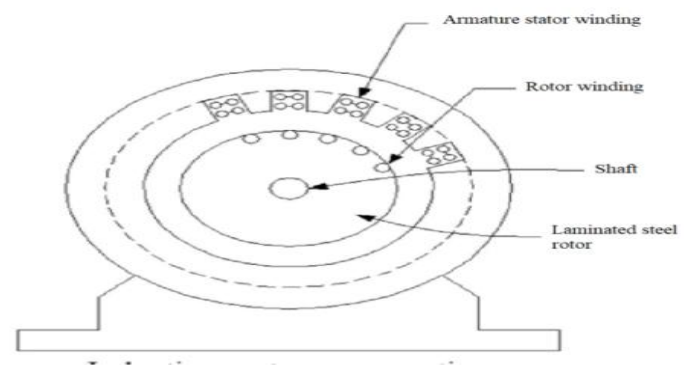

Fig. 1.Induction Motor cross section

\section{INDUCTION MOTOR MODEL}

The induction motor is modelled by consideringrotor, or synchronous speed, or by itsstator. These are called as reference frames. The variables of induction motor, for example current, voltage and flux are referred to the chosen frame for modeling. In this paper, we use stationary reference frame for modeling induction motor. Fig. 2 shows the Induction motor stator current is framed in the role of a vector includes real element in d-axis (direct axis) as well as the imaginary element in q-axis(quadratue axis).

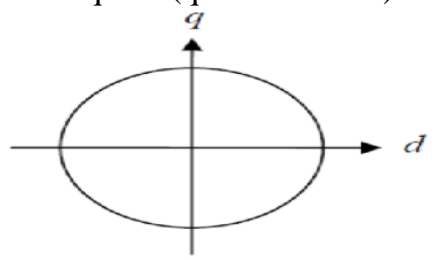

Fig. 2.d-q axes used for modeling induction motor

Three phase voltages supplied to the motor are as follows,

$$
\begin{aligned}
& V_{a s}=V_{m} \sin \left(\omega_{e} t\right) \\
& V_{b s}=V_{m} \sin \left(\omega_{e} t-\frac{2 \pi}{3}\right) \\
& V_{b s}=V_{m} \sin \left(\omega_{e} t+\frac{2 \pi}{3}\right)
\end{aligned}
$$

where, $\mathrm{V}_{\mathrm{m}}$ is the amplitude of applied voltage,

$\omega_{\mathrm{e}}$ is the frequency of supply.

The dynamic performance of induction motor using actual machine variables is difficult due to mutual coupling within the rotor and stator circuits. Fig. 3 shows the asynchronous motor modeling in $\mathrm{d}-\mathrm{q}$ axes.

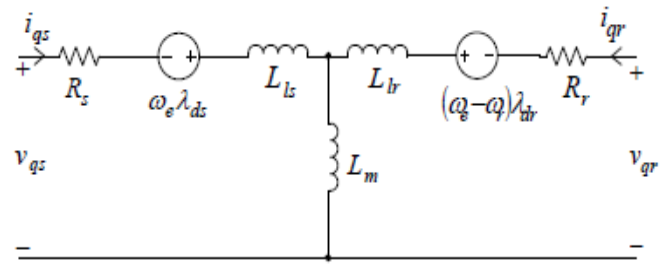

Fig. 3.a.d-axes equivalent crcuit

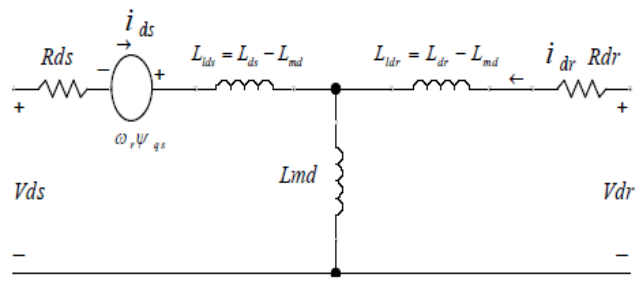

Fig. 3.b.q-axes equivalent circuit

The quantities of the asynchronous motor modelled within the $\mathrm{d}-\mathrm{q}$ axis are as follows:

$\mathrm{R}_{\mathrm{s}}, \mathrm{R}_{\mathrm{r}}$ : Stator and Rotor Resistances.

$\mathrm{L}_{\mathrm{s}}, \mathrm{L}_{\mathrm{r}}$ : Stator and Rotor inductances.
$\mathrm{L}_{\mathrm{m}}$ : Magnetizing inductance.

$\psi_{\mathrm{ds}}, \psi_{\mathrm{qs}}:$ stator flux in d-q axis.

$\psi_{\mathrm{dr}}, \psi_{\mathrm{qr}}$ : rotor flux in d-q axis.

$\mathrm{i}_{\mathrm{ds}}, \mathrm{i}_{\mathrm{qs}}$ : stator current in $\mathrm{d}-\mathrm{q}$ axis.

$\mathrm{i}_{\mathrm{dr}}, \mathrm{i}_{\mathrm{qr}}$ : rotor current in $\mathrm{d}-\mathrm{q}$ axis.

$\mathrm{V}_{\mathrm{ds}}, \mathrm{V}_{\mathrm{qs}}$ : stator voltages in $\mathrm{d}-\mathrm{q}$ axis.

Stator voltage equations are,

$$
\begin{aligned}
& \frac{d}{d t} \psi_{d s}=\mathrm{V}_{\mathrm{ds}}-\mathrm{R}_{\mathrm{s}} \mathrm{i}_{\mathrm{ds}} \\
& \frac{d}{d t} \Psi_{q s}=\mathrm{V}_{\mathrm{qs}}-\mathrm{R}_{\mathrm{s}} \mathrm{i}_{\mathrm{qs}}
\end{aligned}
$$

Rotor voltage equations are,

$$
\begin{aligned}
& \frac{d}{d t} \psi_{d r}=\mathrm{V}_{\mathrm{dr}}-\mathrm{R}_{\mathrm{r}} \mathrm{i}_{\mathrm{dr}}-\omega_{\mathrm{r}} \psi_{\mathrm{qr}}=0 \\
& \frac{d}{d t} \psi_{q r}=\mathrm{V}_{\mathrm{qr}}-\mathrm{R}_{\mathrm{r}} \mathrm{i}_{\mathrm{qr}}-\omega_{\mathrm{r}} \psi_{\mathrm{dr}}=0
\end{aligned}
$$

Stator currents,

$$
\begin{aligned}
& \psi_{d s}=L_{s} i_{d s}+L_{m} i_{d r} \\
& \psi_{q s}=L_{s} i_{q s}+L_{m} i_{q r}
\end{aligned}
$$

Rotor currents

$$
\begin{aligned}
& \Psi_{d r}=L_{r} i_{d r}+L_{m} i_{d s} \\
& \psi_{q r}=L_{r} i_{q r}+L_{m} i_{q s}
\end{aligned}
$$

Torque developed by induction motor is,

$$
\mathrm{T}_{\mathrm{e}}=\frac{3}{2} \frac{P}{2} L_{m}\left(i_{q s} \psi_{d s}-i_{d s} \psi_{q s}\right)
$$

Swing equation represents the speed and torque relation,

$$
\left(\frac{2}{P}\right) J \frac{d \omega_{r}}{d t}=\mathrm{T}_{\text {shaft }}-\mathrm{T}_{\mathrm{e}}
$$

Using (4) to (13), induction motor is modelled using MATLAB/Simulink as shown in Fig. 4 and is fed by a three phase inverter.

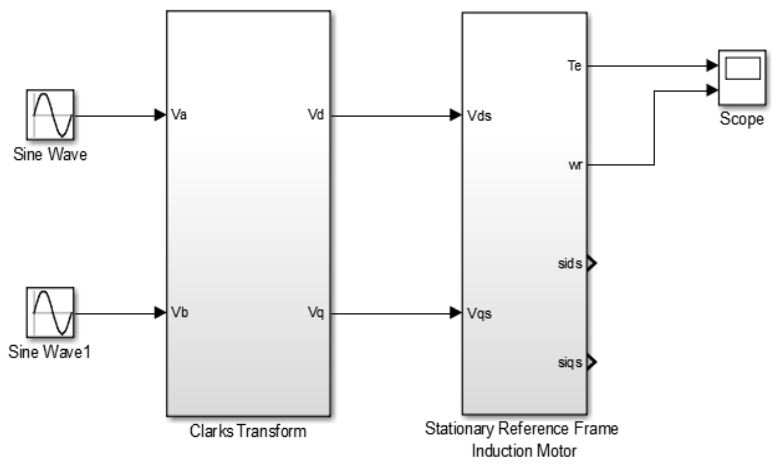

Fig. 4.Induction Motor Model in Simulink

Since rotor is shorted because of squirrel cage rotor, stator voltages are used as the control inputs.

\section{BLOCK DIAGRAM OF DTC}

In 1984, Direct Torque Controlfor induction motor was introduced by Takahashi in Japan and later on in Germany by Depenbrock in 1985 . Contradictory to the traditional vector control, DTC doesn't need any combine transformation, Proportional Integral controllers, Pulse Width Modulation and position encoders. Therefore DTC is much more facile as compared to other control techniques. Furthermore, DTC and vector control provides better dynamic response whereas DTC is not so much reactive for variation in the motor parameters. 
Fundamentally, both torque as well as stator flux needs to-be calculated whereas these values can be used for direct control within the hysteresis band and for maintaining the values close to desired value.

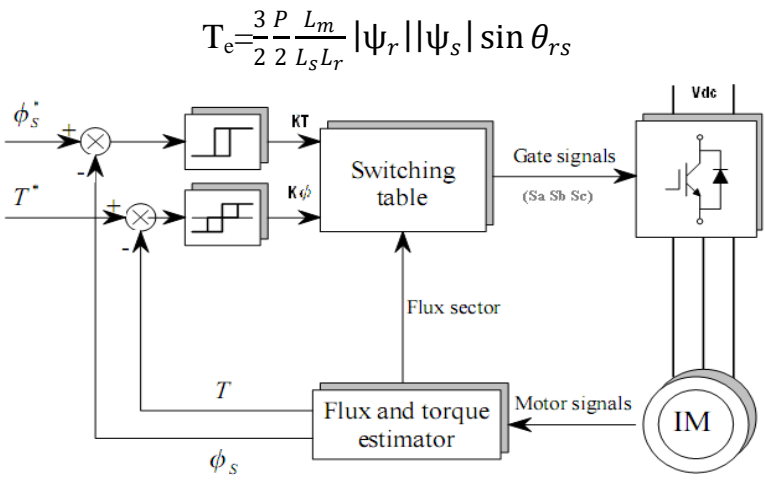

Fig. 5.DTC Block diagram with Inverter fed IM

\section{DESIGN OF FEEDBACK SYSTEM}

The reference stator flux as well as torque is to be individually controlled.

\section{A. Hysteresis Flux Controller}

The stator voltage is applied according to that stator flux varies during the interval of time. Therefore the stator flux can be controlled by choosing desirable voltage vector. Fig 6 shows the flux plane of stator is partitioned into six sectors, where every sector has the separate voltage vectors. In the figure bold arrow describes the reducing of stator flux at the same time the light arrow describes the increasing of the stator flux.

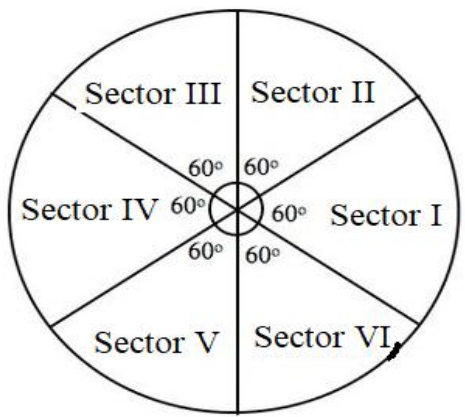

Fig. 6.Six sectors with the distinct voltage vectors

The calculated stator flux is increased or decreased in sequence to track the reference stator flux. However, the 2-level hysteresis controller shown in Fig. 7 is used to provide better model.

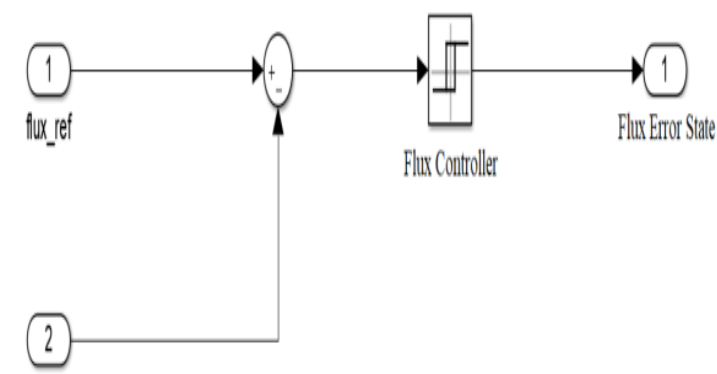

fux calculated

Fig. 7. Two level hysteresis flux controller

\section{B. Torque Controller}

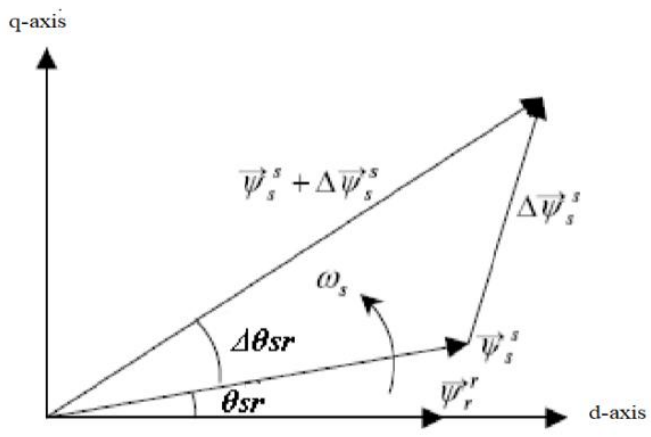

Fig. 8.Stator and Rotor space vectors

The Fig. 8 shows that when the flux in stator varies speedily, then $\theta_{\text {sr }}$ will also varies continuously and causes a very high change in the output torque. Similarly as hysteresis flux control, torque is limited inside the hysteresis band of 3-level shown in Fig. 9.

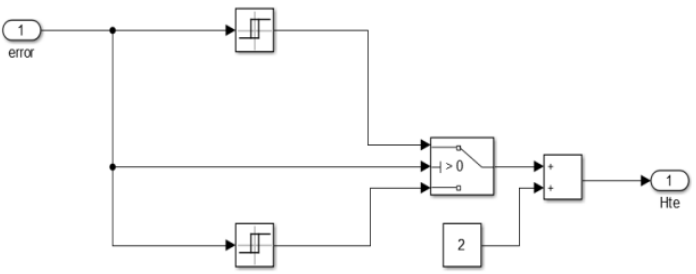

Fig. 9. Three level hysteresis control

In DTC, Induction Motor can conduct in any one of the four quadrants in torque - speed plane.

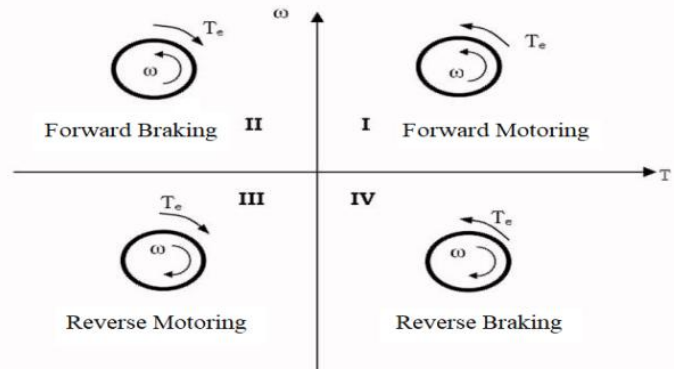

Fig. 10.Four quadrant operation of drives

The induction motor can work in all the four quadrants as shown in Fig. 10.

\section{MODELING OF INVERTER}

The inverter is a power converter which converts the DC supply into proposed AC supply with or without varying frequency. The following equations are used to model the inverter.

$$
\begin{aligned}
& \mathrm{V}_{\mathrm{A}}=\frac{V_{d c}}{3}\left[2 S_{a}-S_{b}-S_{c}\right] \\
& \mathrm{V}_{\mathrm{b}}=\frac{V_{d c}}{3}\left[2 S_{b}-S_{a}-S_{c}\right] \\
& \mathrm{V}_{\mathrm{c}}=\frac{V_{d c}}{3}\left[2 S_{c}-S_{b}-S_{a}\right]
\end{aligned}
$$

Equations(14), (15), and (16)are used to model the inverter in simulink 


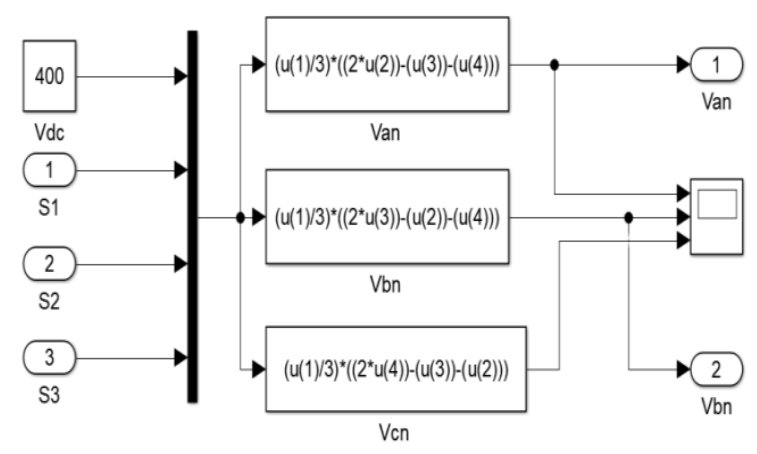

Fig. 11.Model of Inverter

Table- II: Switching sectors for inverter voltage vector

\begin{tabular}{|c|c|c|c|c|c|c|c|}
\hline \multicolumn{2}{|c|}{ Error status of } & \multicolumn{7}{|c|}{ Sector no. } \\
\hline \multirow{3}{*}{$\psi_{s}$} & $\mathrm{~T}_{\mathrm{e}}$ & $\begin{array}{c}1 \\
\theta_{\mathrm{s} 1}\end{array}$ & $\begin{array}{c}\theta_{\mathrm{s} 2} \\
\theta_{\mathrm{s} 3}\end{array}$ & $\theta_{\mathrm{s} 4}$ & $\theta_{\mathrm{s} 5}$ & $\theta_{\mathrm{s} 6}$ \\
\hline \multirow{3}{*}{0} & 1 & 110 & 010 & 011 & 001 & 101 & 100 \\
\cline { 2 - 8 } & 0 & 111 & 000 & 111 & 000 & 111 & 000 \\
\cline { 2 - 8 } & -1 & 011 & 001 & 101 & 100 & 110 & 010 \\
\hline \multirow{3}{*}{1} & 1 & 100 & 110 & 010 & 011 & 001 & 101 \\
\cline { 2 - 8 } & 0 & 000 & 111 & 000 & 111 & 000 & 111 \\
\cline { 2 - 8 } & -1 & 001 & 101 & 100 & 110 & 010 & 011 \\
\hline
\end{tabular}

The space vector takes 8 values as shown in Fig. 12. In the 8 voltage vectors, 6 voltage vectors are non-zero vector and 2 voltage vectors are zero vectors.

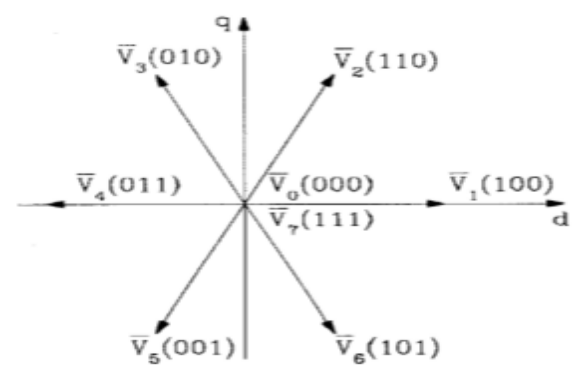

Fig. 12.Inverter switching states

Table- I: Switching table for inverter

\begin{tabular}{|c|c|c|c|c|c|}
\hline Sl.No & State & $\mathrm{S}_{\mathrm{a}}$ & $\mathrm{S}_{\mathrm{b}}$ & $\mathrm{S}_{\mathrm{c}}$ & Vector \\
\hline 1 & 0 & 0 & 0 & 0 & $\mathrm{~V}_{0}$ \\
\hline 2 & 1 & 1 & 0 & 0 & $\mathrm{~V}_{1}$ \\
\hline 3 & 2 & 1 & 1 & 0 & $\mathrm{~V}_{2}$ \\
\hline 4 & 3 & 0 & 1 & 0 & $\mathrm{~V}_{3}$ \\
\hline 5 & 4 & 0 & 1 & 1 & $\mathrm{~V}_{4}$ \\
\hline 6 & 5 & 0 & 0 & 1 & $\mathrm{~V}_{5}$ \\
\hline 7 & 6 & 1 & 0 & 1 & $\mathrm{~V}_{6}$ \\
\hline 8 & 7 & 1 & 1 & 1 & $\mathrm{~V}_{7}$ \\
\hline
\end{tabular}

In Fig. 11 and Table- I, 1 signifies that the switch is in on condition as well as 0 signifies that the switch is in off condition. $S_{a}, S_{b}, S_{c}$ are the combination of switches. Since including the sectors shown in Fig. 12, switching sectors of stator flux can be formed in the following ways.

$$
\begin{gathered}
-30^{0}<\theta_{s 1}<30^{0} \\
-30^{0}<\theta_{s 1}<90^{0} \\
-90^{0}<\theta_{s 1}<150^{0} \\
-150^{0}<\theta_{s 1}<210^{0} \\
-210^{0}<\theta_{s 1}<270^{0} \\
-270^{0}<\theta_{s 1}<330^{0}
\end{gathered}
$$

The stator flux, torque and the flux hysteresis are utilized to decide, desirable stator flux sector to give the exact value of voltage vectors to the asynchronous ac motor functioning under DTC. The selection of voltage vectors in all the possible conditions of torque and flux comparator is provided in Table II.

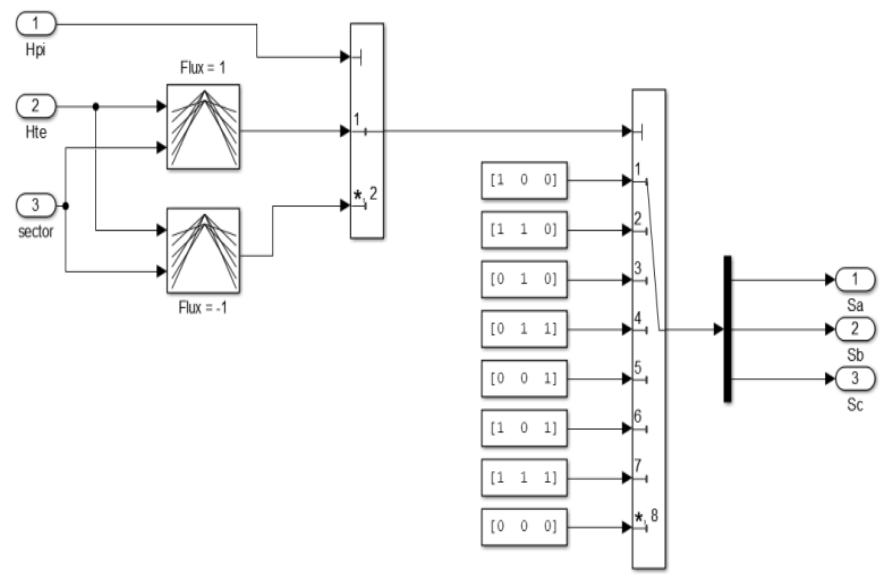

Fig. 13.Switching Process

VII. CASE STUDY

A $3 \mathrm{~kW}, 4$ pole induction motor is utilized for testing the fulfillment of the described design. Table-III shows the asynchronous motor constants.

Table- III: A 3 KW Induction motor parameters

\begin{tabular}{|c|c|}
\hline Parameter & Value \\
\hline $\mathrm{R}_{\mathrm{S}}$ & $0.4350 \Omega$ \\
\hline $\mathrm{R}_{\mathrm{r}}$ & $0.8160 \Omega$ \\
\hline $\mathrm{L}_{\mathrm{s}}$ & $0.0020 \mathrm{H}$ \\
\hline $\mathrm{L}_{\mathrm{r}}$ & $0.0020 \mathrm{H}$ \\
\hline $\mathrm{L}_{\mathrm{m}}$ & $0.0693 \mathrm{H}$ \\
\hline Inertia, J & $0.0890 \mathrm{Kg} \mathrm{m}^{2}$ \\
\hline No of Poles & 4 \\
\hline Applied Voltage & $400 \mathrm{~V}($ line to line $)$ \\
\hline Frequency & $60 \mathrm{~Hz}$ \\
\hline
\end{tabular}




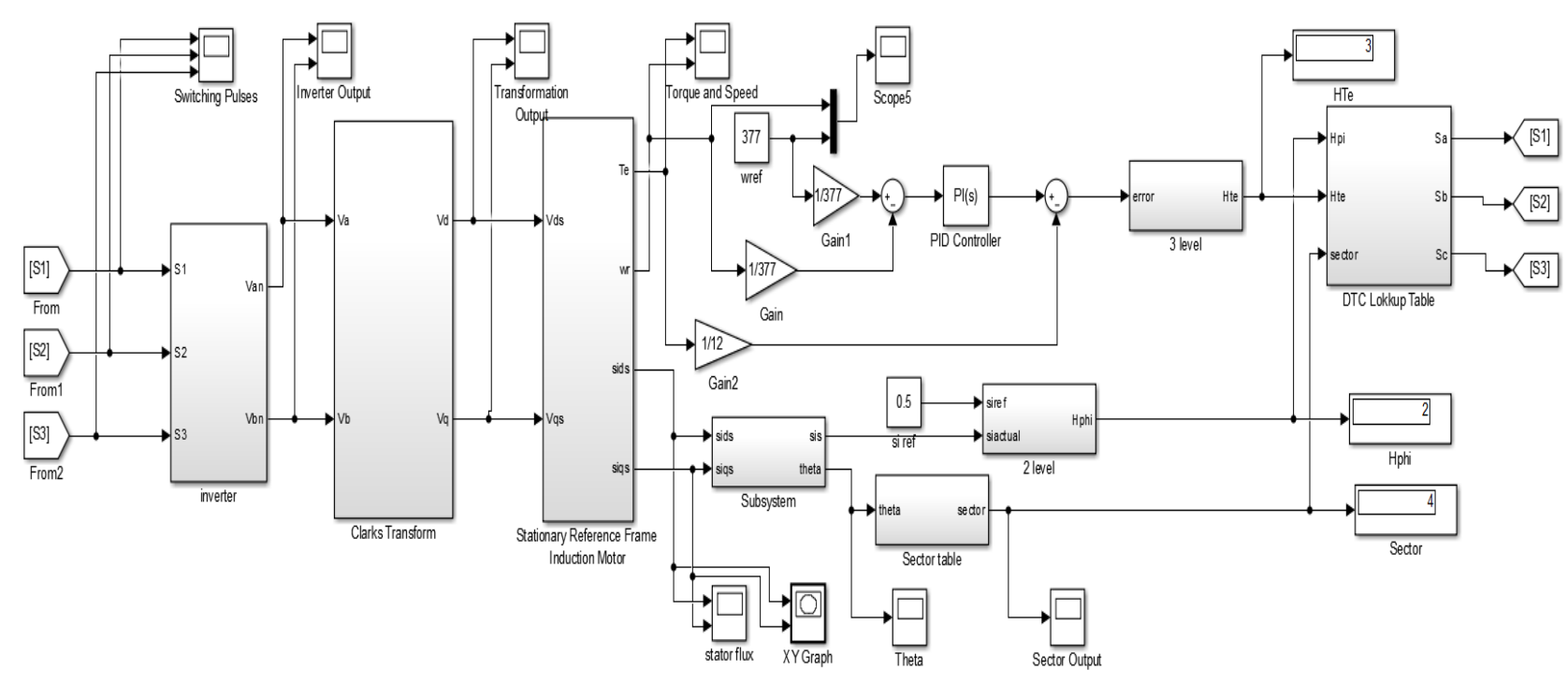

Fig. 14.Induction Motor Model with Direct Torque Control in simulink/MATLAB

\section{SIMULATION RESULTS}

To study the induction motor operating in transient conditions, a simulation of induction motorwith direct toque control method is demonstrated. At time, $\mathrm{t}=0$ the induction motor is stand still. The load torque is initially kept zero and then varied and the load torque is made $25 \mathrm{~N}-\mathrm{m}$. Figure shows the results of simulation using simulink model.

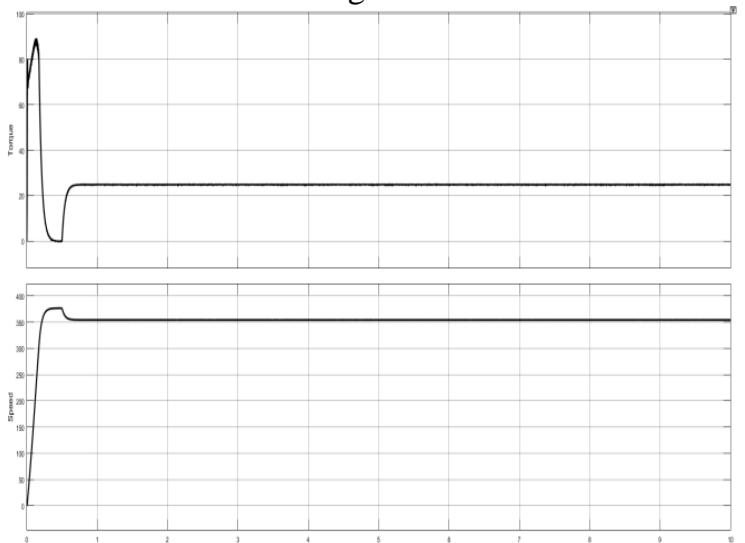

Fig. 15.Waveforms shows the motor torque Te (upper) and speed $\omega_{\mathrm{r}}$ (lower) in $\mathrm{rad} / \mathrm{sec}$. Note that if the load torque increases to $25 \mathrm{~N}-\mathrm{m}$, the speed decreases slightly from 375 $\mathrm{rad} / \mathrm{sec}$ to $350 \mathrm{rad} / \mathrm{sec}$.

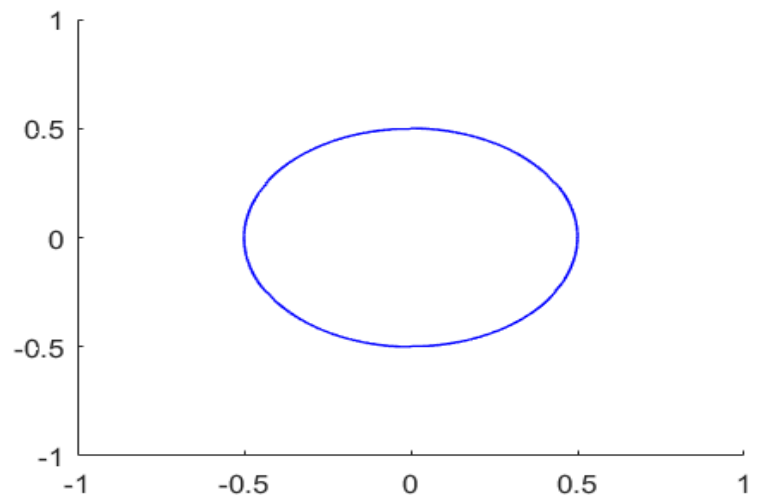

Fig. 16.Flux vector trajectory for direct torque control

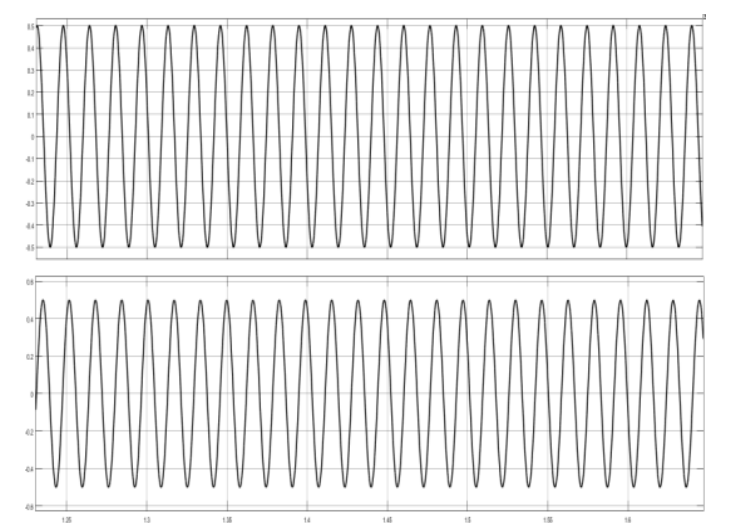

Fig. 17.Flux Vector waveforms for DTC

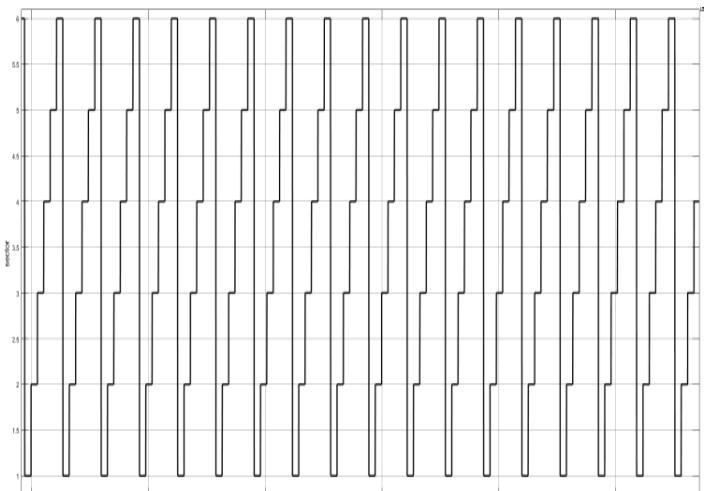

Fig. 18.Switching Process waveform

\section{CONCLUSION}

In this paper the direct torque control for asynchronous motor is modeled and simulated in MATLAB/Simulink as well as tested successfully by checking the parameters such as $\mathrm{d}$ as well as q stator currents, $\mathrm{d}$ and $\mathrm{q}$ axes flux, speed and torque. 
From the Fig. 15, we observe that developed DTC model has achieved high dynamic performance with respect to immediate changein speed response corresponds to change in the demand torque. Therefore DTC for asynchronous motor drive is more simpler because it does not require any motor parameters apart from the stator resistance.

\section{REFERENCES}

1. Blaschke, F., "The principle of field orientation as applied to the new transvector closed loop system for rotating field machines", Siemens Review, Vol.39, no.3, pp. 217 -220, May 1972.

2. Alnasir.Z.A., "Design of Direct Torque Controller of Induction Motor", Vol 4, no 2, Apr-May 2012.

3. VikramarajanJambulingam, "Direct Torque Control Design of Three Phase Induction Motor", IEEE Conf. Power Electronics and Variable speed Drives, May 2002.

4. Karlis, A.D., Kiriakopoulos, K., Papadopoulos, D.P., and Bibeau,E.L., " Comparison of the Field Oriented and Direct Torque Control Methods for Induction Motors used in Electric Vehicles", Democritus University of Thrace.

5. M. Godoy Simoes, Felix A Farret, "Modelling and Analysis with induction motor", $3^{\text {rd }}$ edition, New York: CRC Press, 2000

6. Silva, N.M., Martins, A.P., and Carvalho, A.S., "Torque and Speed Modes Simulation of A DTC Controlled Induction Motor", Proceedings of the 10th IEEE Mediterranean Conference on Control Automation, MED'2002, Lisboa, pp. 1-6, July 2002.

7. Kumsuwan Y, Premrudeepreechacharn S, Toliyat H. Modified direct torque control method for induction motor drives based on amplitude and angle control of stator flux. Electric Power Systems Research, 2008.

8. A. Ouarda and F. Ben Salem, "Induction Machine DTC-SVM A Comparison Between Two Approaches" Proc. 10th International Multi-Conference on Systems, Signals \& Devices (SSD), 2013, pp. 278-282.

9. B.K.Bose,"Modern power electronics and AC drives." New Delhi, PHI Learning Private Limited, 2011.pp.413-408

10. Krause, P. C., Wasynczuk, O. and Sudhoff, S. D., Analysis of Electric Machinery, IEEE(1995).

11. P.M. Palmpankar, R U. Ghanmare, "Generalized dynamic model of induction motor using simulink”,ITSI TEEE, Vol-1, Issue-5,2013.

12. Anthony Purcell, P. Acarnley, "New Direct Torque Control Scheme of Induction Motor for Electric Vehicle" Proceeding of control conference, 5th Asian, Vol.2, 2004.

\section{AUTHORS PROFILE}

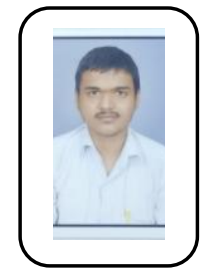

Chinmaya Kulkarni,was born in Nargund, Karnataka, India in 1998. He is currently pursuing undergraduation in the Department of Electrical and Electronics Engineering, KLE Technological University, Hubballi, India. His area of interest includes Embedded Systems, Power Electronics,Electric Drives and Control, Digital Electronics and Power System.

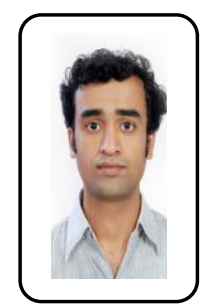

GurubasuHombal: Cuurently working as Assistant Professor in the department of Electrical and Electronics Engineering at K.L.E Technological University Hubballi. $\mathrm{He}$ received his Bachelor's degree in Electrical and Electronics Engineering and Master's degree in Power Electronics from VTU-Belagavi. His areas of interest are Power Electronics, Electric Drives and Control and E-mobility.

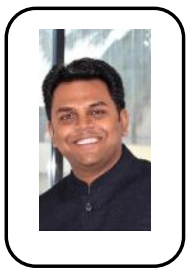

Sachin Angadi:He completed B.E (Electrical and Electronics Engineering) from B.V.Bhoomaraddi College of Engineering \& Technology, Hubballi in 2011 and M.Tech.( Computers Application in Industrial Drives ) from The National Institute of Engineering, Mysore in 2013. He has worked as project trainee in ISRO Satellite Centre (ISAC), Bangalore (24-08-2012 to 27-05-2013). $\mathrm{He}$ has over five years of teaching experience. He is presently working as Assistant Professor in the Department of Electrical \& Electronics Engineering at KLE Technological University, Hubballi. He has presented several papers in International
Conferences. His areas of work are power electronics, Electric drives, and Renewable energy systems.

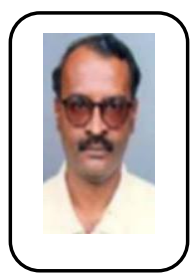

Dr. A. B. Raju: Currently working as a Professor and Head, Department of Electrical and Electronics Engineering, B. V. B. College of Engineering and Technology Campus, K. L. E. Technological University, Hubballi. He obtained his B. E. in Electrical Engineering from Karnatak University, Dharwad in the year 1985, M. Tech. in Machine Drives and Power Electronics from IIT, Kharagpur in 1993 and Ph.D. from IIT, Bombay in the year 2005. His research interest are in the areas of power electronic systems, electric drive vehicles and renewable energy systems. 